\title{
Methodical foundations of the preparation of highly valued personnel for high-rise construction
}

\author{
Svetlana Belyaeva ${ }^{1, *}$, Oksana Belyantseva ${ }^{1}$, Nataliya Safonova $^{2}$, Olga Vasilyeva $^{3}$ \\ ${ }^{1}$ Voronezh State Technical University, Moscow Avenue, 14, Voronezh, 394026, Russia \\ ${ }^{2}$ State University of Marine and River Fleet in the name of admiral S.O. Makarov (Voronezh branch), \\ Leninsky pr., 174 "L", Voronezh, 394033, Russia \\ ${ }^{3}$ Moscow State University of Civil Engineering, Yaroslavskoe sh. 26, Moscow, 129337, Russia
}

\begin{abstract}
When carrying out design and survey and construction and installation works for such an innovative type of activity as high-rise construction, the problem of personnel qualification becomes urgent. The article poses a research problem, identifies the main reasons for the need for training highly qualified specialists in construction, and suggests areas for improving training. The expediency of development of mentoring system was proved, the corresponding model of interaction between educational institutions and construction enterprises was offered, key interaction effects were evaluated.
\end{abstract}

\section{Introduction}

Globalization and unification of the world economy, the active formation of the market system of management in Russia, the specificity of the current stage of scientific and technical progress [1] make it necessary to pay special attention to the problem of improving the workforce and ensuring its compliance with modern social and economic requirements.

Improvement of higher education, maintenance of its quantitative and qualitative characteristics at a level that meets all modern requirements of building science and practice is a necessary condition for high-quality and safe performance of works, an important factor in ensuring safety, environmental friendliness, energy efficiency and intellectuality of highrise buildings.

On the basis of data of the amount, quality, structure of highly skilled specialists in construction and their use, it is necessary to determine the real need for them for the type of activity, and hence the scale of their reproduction [2].

The problem of improving the training of specialists in the system of Russian higher education in the construction sector is of great importance, at least for 4 reasons:

1) to improve the quality of education in general;

2) to improve the quantitative, structural and qualitative characteristics of the workforce;

3) for the successful and civilized development of the construction industry;

4) to ensure economic stability and economic growth.

\footnotetext{
* Corresponding author: belyaeva-sv@mail.ru
} 
Note that all these moments are interrelated and interdependent, and the urgency of the problem of increasing the efficiency of reproduction of workers with higher education is not only great but also obvious, predetermined by the very content of the category "highly qualified specialists", by the huge role that they play in the economy[3] .

This problem has two interrelated aspects - quantitative and qualitative [4]. But the improvement of the quality of the workforce in accordance with the current level of scientific, technical and cultural achievements in the society, the trends in their development, and changes in the socioeconomic nature is of particular relevance [5].

Many studies confirm that the insufficiently high quality of the labor force, firstly, leads to its accelerated physical and moral aging, and secondly, causes crisis and regressive conditions in all spheres of society, but primarily in the economy [6]. Thus, the improvement of the quality and structure of the workforce should become an important part of the current stage of development of the Russian economy.

\section{Materials and Methods}

The main direction of the improvement of the quality of workforce, in our view, is the improvement of its educational and professional training, which includes the development of the following elements:

- a system of general and vocational education aimed at training new workforce;

- systems for in-house training of personnel, including workplaces, as well as "pointed", "targeted" training of interns (for example, graduates of higher education institutions);

- Self-study and distance learning systems with appropriate conditions;

- a continuous education system aimed at preserving and improving the workforce;

- systems of vocational guidance and psychological support for young people, unemployed citizens, as well as those who are employed, but who wish to change the work profile;

- services of the employment service for training unemployed citizens, as well as a mechanism for supporting and organizing advanced training for workers at risk of dismissal.

Let us dwell on some of these problems in more detail. First of all, it should be noted that the Russian multifunctional system of general and professional education, retraining and advanced training of personnel is going through a difficult period of reform. At the same time, changes in the education system are largely inadequate to changes in the labor market [7]. State educational structures, which have a rich experience of teaching adolescents, often can not organize effective adult training.

Thus, changes in the system of vocational education should be directed to meet the needs of the population for professional educational services, but also they should take into account the corresponding needs of regional economies and the development trends of regional labor markets [8].

According to the survey of employers, it was found that the average period of adaptation to work in a team of a graduate of a technical college is 1-3 years (the main reasons are a low level of development of "flexible skills" - the ability to work in a team, negotiate, find an approach to people, persuade, make decisions independently, select and use relevant information, etc., as well as "lag" in technical knowledge and corresponding "hard skills" from the real level of innovation development (because from the moment of introduction of innovation at a particular enterprise before it is included in the relevant normative and technical documents, and, accordingly, in lecture courses, takes place, in particular, in construction, 1-2 years). 


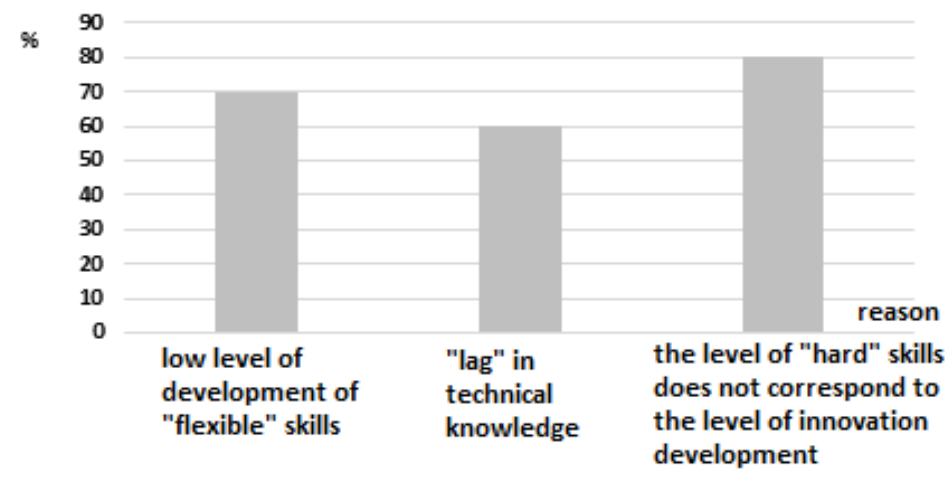

Fig. 1. Results of the survey of employers on the reasons for the duration of adaptation of graduates of higher education institutions in the collective of the enterprise

As a solution to existing problems, we consider it expedient to introduce a mentoring mechanism in the university. Mentoring is an activity for the individualization of education aimed at clarifying the educational motives, professional interests and competences of the student, choosing educational resources for creating an individual educational trajectory, working on professional orientation, forming the educational and professional reflection of the student.

An experienced employee of an educational organization or an employee of a partner enterprise can be a mentor [9]. The subject of mentoring is the formation and implementation of an individual educational trajectory of students, starting with the diagnosis of the basic competences of talented people and including the process of support after employment.

The basis of the proposed model of the mentoring system is the construction of the goal of the educational trajectory (work with tutors and staff of partner enterprises) and the individualization of the educational trajectory by including services for the development of "flexible" skills (coaching, training of emotional intelligence, business simulation, open lectures, webinars, etc.) and the rapid development of innovative professional competencies and the specifics of more narrowly professional activities (mentoring of an employee as a rule, university graduates) on the basis of a preliminary assessment center for identifying "strong" and "weak" parties to the participants, and conducting gaming sessions to introduce into the profession with the final formation and promotion of the resume (or the support of a business project ).

In general, the model of the mentoring system in the educational organization is presented in Figure 2.

We also consider it expedient to create a single information and communication platform on the website of an educational organization that must contain the following necessary services and accumulate them in one place:

- portfolio of participants;

- database of planned contests, grants, conferences;

- database of mentors (describing their career success and the skills that they needed);

- database of winners of competitions, participants in projects of an educational organization, etc. (associated with the portfolio, infographics of quantitative indicators);

- database summary "Gold reserve personnel";

- database of enterprises-partners, employers and enterprises inviting students for practice; 


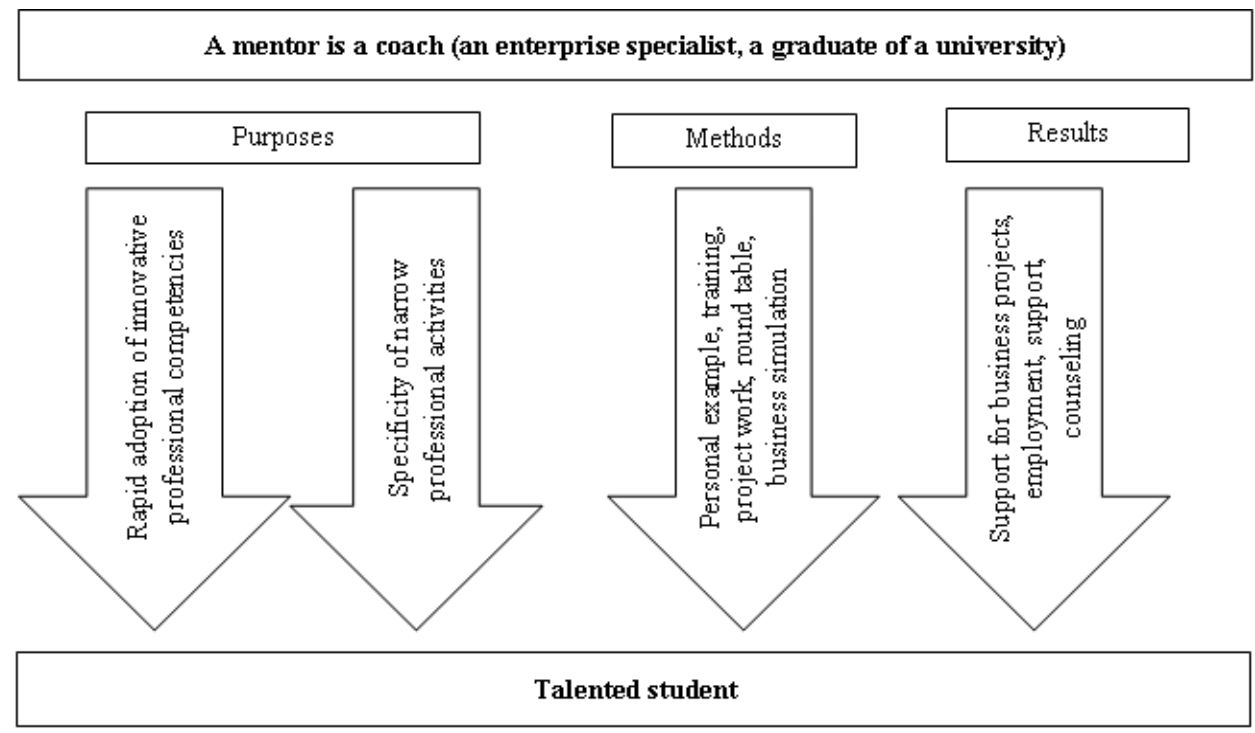

Fig. 2. Conceptual model of the mentoring system in the educational organization of the construction profile

- chat rooms for participants and mentors;

- e-learning resources and links;

- database of projects implemented by the educational organization and its partners;

- information from mentors;

- access to the service of distance educational technologies.

Mentor system consists of following. The tutor (specialist of the educational organization) helps to develop an individual trajectory of learning based on the planned goal and the results of individual evaluation (with the exception of the formation of an individual curriculum that includes participation in certain activities to form the necessary "soft" and "tough" skills, conferences, etc., obtaining additional education or professional retraining, upgrading skills for certain programs) and adjust it for the participants that are involved in the project (taking into account the impact of the participant is determined by results of participation in project activities and business modeling).

The mentor-coach (the specialist of the enterprise-partner, as a rule, the graduate of the educational organization) carries out certain measures for the formation and improvement of innovative professional competencies (personal example, open lectures, round tables, master classes, etc.), introduction to the specifics of activities enterprise, conducts project activities with participants of the relevant focus, accompanies the participant after employment for this enterprise, conducts consultations, may initiate topics, assignments for the implementation of project activities of participants. By the decision of the mentor the participant can be employed at the enterprise even before the end of the training.

In general, a block diagram of the algorithm for implementing the mentoring system in an educational organization is presented in Figure 3. 


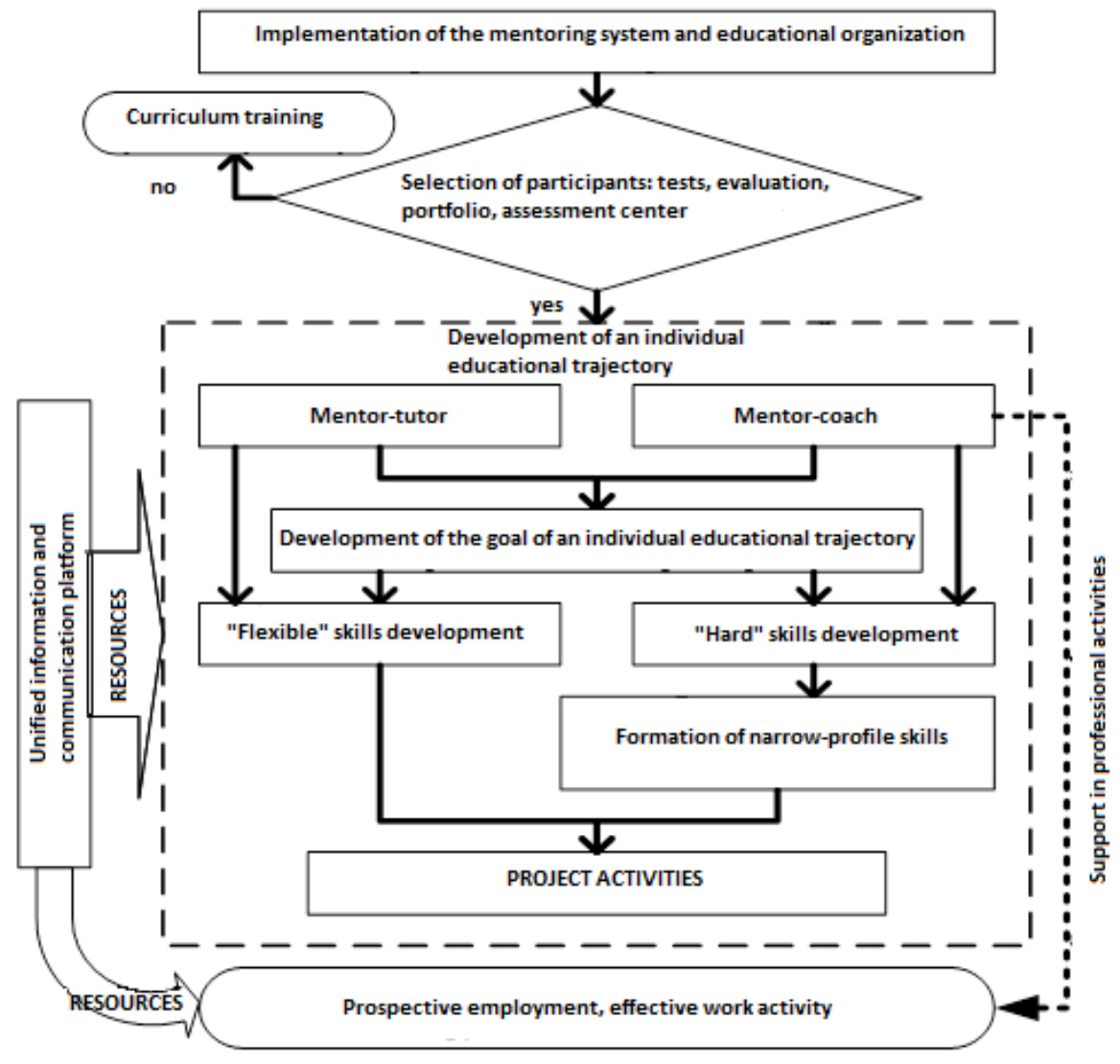

Fig. 3. Block diagram of algorithm for implementing the mentoring system in educational organization

From the consideration of the problem of improving the quality of training of workers in educational institutions, we turn to the problem of improving the workforce at enterprises and organizations.

It is known that the qualitative level of employees of Russian enterprises and organizations is significantly inferior to the requirements imposed on the international labor market.

Most of trainde workers in the process of finding work face the need to either upgrade their existing qualifications or acquire a new specialty. However, employers who are experiencing financial difficulties do not pay attention and do not show interest in upgrading their employees' skills. Volumes of in-house training are constantly shrinking.

Training programs for employees at enterprises are focused mainly on obtaining primary qualifications, there are practically no training programs for highly skilled workers.

Insufficient attention is paid to motivation of employees to improve their professional and qualification level, there are practically no managers and other specialists dealing with issues of in-house training and having for this purpose special training.

Practice shows that the minimum costs necessary for a simple reproduction of the professional potential of the enterprise must be at least $1.5 \%$ of the wages paid [10]. However, at present they are $0.5-0.7 \%$, that is $2-3$ times less than the minimum.

From what has been said, it is necessary to restore and develop the system of in-house training with the appropriate state support. A number of measures can be proposed in this regard. Let's name some of them. 
First, relying on the positive experience of developed countries, it would be necessary to introduce a system of certification of workers in the Russian Federation, which, in our view, would significantly improve the quality and competitiveness of the workforce [11]. Such practice, based on the system of certification of employees of enterprises and organizations, exists in Russia, but requires significant changes and additions in accordance with global trends and modern features of the domestic economy.

Secondly, the experience of the mentoring system should be extended to the organization of training in the workplace.

Third, the role of system of professional development and professional retraining should be strengthened.

Fourth, a system for monitoring the level of quality of the workforce should be introduced. In this regard, there are a number of indicators for the characterization of highly skilled specialists. However, a harmonious system of interrelated quantitative and qualitative indicators, full and versatile characterizing specialists, has not yet evolved. In addition, based on the existing realities, conditioned by the cardinal social and economic transformations in the country and the constant development of scientific and technical progress, the available indicators have to be adjusted and supplemented. At the same time, special attention should be given to the indicators characterizing the level of training of specialists, as well as unemployment and migration among them. Note also that the existing statistical information is extremely poor, irregular, the possibilities of current statistics are limited

\section{Results}

So, the contribution of a specialist with higher education to production and economics is important and very multifaceted: scientific and technical programs and developments, new technology, advanced technologies (including organizational, informational, humanitarian, social), project analysis, etc.

We emphasize that the production function, which characterizes the production process of an individual firm and expresses the patterns and efficiency of allocating its resources, contains indicators of the quantity and quality of highly qualified specialists as the most important characteristics of the labor resources used.

In addition, as a result of implementing the proposed system, both the educational organization and the partner firm receive a number of effects, systematized conceptually in Figure 4.

Accordingly, students participating in the system acquire the necessary "flexible" and "tough" skills, knowledge of innovative technologies, work skills (and, correspondingly, almost $100 \%$ probability of employment) at the mentor's enterprise, the possibility of online communication with participants and mentors (networking), access to the database of information and communication platform services (database of competitions, grants, video recordings of events, links, portfolios and other resources), creating a professional resume and its promotion in HR-agencies of tht region, held at educational conferences Organization of Employers ( "Gold Fund staff"), developed by the implementation of a business project in its compliance criteria on the basis of grant support or creation of small innovative enterprises.

Educational organization is empowered to attract employers, to create a community of graduates and strengthen cooperation with the enterprises that they represent, to increase the share of employed graduates, to strengthen the link between science and production, to promote the organization's brand in the HR community, and to develop new educational resources. 


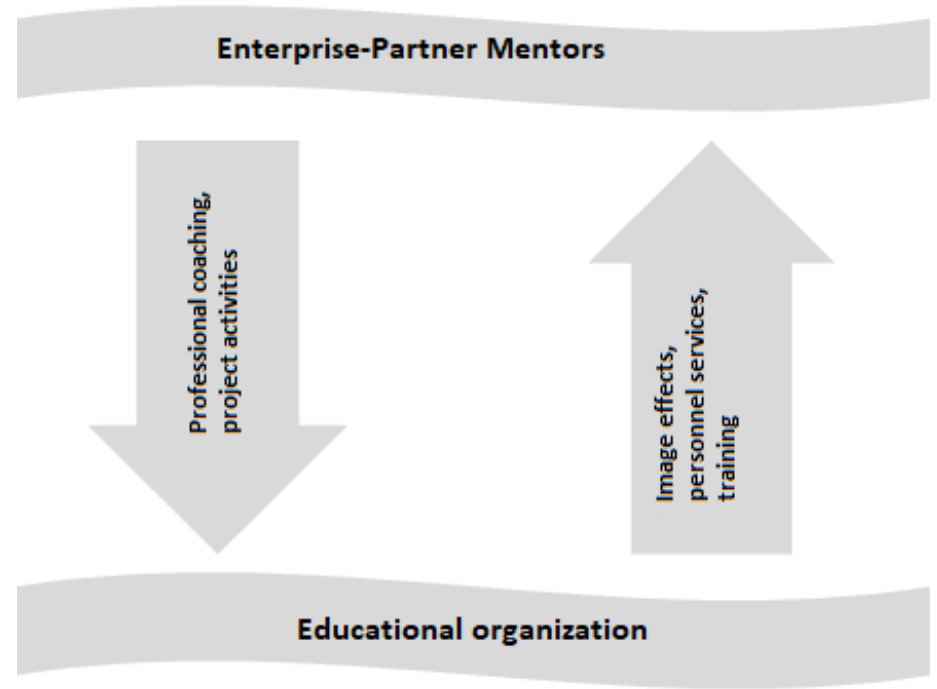

Fig. 4. Effects of the educational organization and the partner enterprise as a result of the introduction of the mentoring system

The effect for the enterprise is to shorten the period of adaptation of new employees (increase in labor productivity), to obtain image effects, to train mentors (including obtaining the necessary skills for mentoring at the workplace), implementation of projects initiated by the enterprise (with cost savings).

As a result, following the fractal construction of the management system for the investment and construction complex, an effect is achieved at the meso level, which consists of the growth of the share of highly qualified graduates remaining at construction enterprises, increase in labor productivity, and increase in competitiveness of construction companies in the region

\section{Discussions}

Taking into account the specifics of modern conditions, we propose to use the following system of indicators to characterize specialists.

First of all, indicators characterizing highly skilled specialists should be divided into two groups:

1) quantitative,

2) qualitative.

In the case of highly qualified specialists, quantitative indicators are indicators of the number of specialists grouped according to a certain trait, and qualitative indicators reflect indicators of the specific set and amount of knowledge and skills acquired by specialists in higher education institutions and then replenished in the course of their professional activities.

Within both groups of indicators (quantitative and qualitative) it is expedient to distinguish three subgroups:

1) indicators characterizing persons with higher education;

2) indicators characterizing highly skilled specialists engaged in the economy;

3) indicators characterizing non-working professionals registered with employment services. 
Note that not all non-working professionals are included in last subgroup, but only those registered with employment services, it is dictated by the need to assess the potential of specialists in the country which actively seek for work and claim the relevant jobs. Information about all non-working professionals can be obtained as a difference between the corresponding indicators of the first and second subgroups.

When studying the quality of specialists at micro level, first of all within the framework of individual enterprises, their associations, sub-sectors, along with the above-mentioned interests, indicators such as length of service: general and specialty; number and structure of specialists by category, etc.

In addition, unemployed, but previously working specialists can be characterized by such an indicator as the average score obtained on the basis of the latest attestation. For a microanalysis of the quality of unemployed professionals who previously worked, such indicator as the length of work: general and specialty can be used.

It should be emphasized that the analysis of the quantitative and qualitative characteristics of specialists can not be conducted in isolation from the analysis of the state and development of higher education, especially in the context.

\section{Conclusion}

It should be noted that in general, the system of indicators proposed for the characterization of highly qualified specialists contains a number of such indicators that reflect not only the availability, but also the use of specialists, which in the first place belongs to the second subgroup of indicators-those characterizing specialists engaged in construction.

Finally, it should be noted that an indicator of the effectiveness of specialists' activity is an original synthesizing indicator reflecting the availability and use of highly qualified personnel, their quantitative and qualitative characteristics.

In order to increase labor productivity, reflecting, among other things, the effectiveness of specialists, it is necessary to introduce a mentoring mechanism in educational organizations and further in the production process. The introduction of mentoring in the educational organization will allow graduates to adapt more quickly and painlessly to the team of the enterprise, to master narrower, close to the specifics of the company's competences, to reduce the gap between the speed of introduction of innovations into practice and coverage in the training process, will reveal the "secrets" of the profession and avoid a lot of mistakes, sometimes fatal, to young specialists.

\section{References}

1. B. Karatop, C. Kubat, Ö. Uygun. Computers \& Industrial Engineering, 86, pp 127-136 (2015)

2. E. E. Makarius, Mahesh Srinivasan Business Horizons, 60 (4), pp 495-505 (2017)

3. H.N. Folz, Tracy L. Sprunger, Amy H. Sheehan, Josephine Aranda, Jasmine D. Gonzalvo. Currents in Pharmacy Teaching and Learning, In press, corrected proof, Available online 12 January 2018

4. V. Kankhva. IOP Conf. Series: Earth and Environmental Science 90012175 (2017) doi:10.1088/1755-1315/90/1/012175

5. L.N. Komyshova, S.I. Sergeeva Tasks and functions of educational systems in conditions of reforming the education system. Modern education: content, technology, quality. pp 162-163 (2011)

6. M.C. Meyers, M. Woerkom. Journal of World Business, 49(2), April 2014, Pages 192203 
7. P.R. Sparrow, H. Makram Human Resource Management Review, 25(3), (2015)

8. E. Nezhnikova Procedia Engineering 165 1300-1304 (2016) doi 10.1016/j.proeng.2016.11.854

9. S.S. Gutman, I.M. Zaychenko, O.V. Kalinina, Selection of strategy implementation tool for shipbuilding cluster of Arkhangelsk Oblast Proc. of the 29th IBIMA Conf. Education Excellence and Innovation Management through Vision 2020, pp 1430- 1438 (2017)

10. I.V. Ilin, O. Kalinina, O. Iliashenko, A. Levina, Procedia Engineering, 165, pp 16831692 (2016) DOi- 10.1016/j.proeng.2016.11.910

11. V.I. Churkin, O.V. Kalinina, Estimation of excess burden of labor taxation in Russia, Actual Problems of Economics, 184, IS 10, pp 278- 282 (2016) 